\title{
Algorithm Design of Navigation Intention Message Transmission for Collision Avoidance of Maritime Autonomous Surface Vehicle
}

\author{
Ho Namgung, Kwang-Il Kim, Keon Myung Lee
}

\begin{abstract}
For safe navigation of ship at sea, it is essential to provide navigation intention message to target ship for collision avoidance. Therefore it must be considered for the MASS to transmit navigation intention message to the target ship after making a decision of method for collision avoidance in the encountering situation. This paper presents an algorithm of navigation intention message transmission through the MASS, which is able to evaluate the risk of collision and apply international regulations for collision avoidance. The Fuzzy inference system is used to assess the risk of collision. In case that the risk of collision exceeds the pre-designated threshold, the navigation intention message is transmitted from the MASS to the target ship. Before the collision situation occurs, the target ship is possible to be aware of the navigation intention from the MASS. Proposed the algorithm contributes to providing systematic information exchange between the MASS and the target ship.
\end{abstract}

Keywords: Maritime Autonomous Surface Ship (MASS), Fuzzy Inference System (FIS), Collision Risk (CR), Navigation Intention Message

\section{INTRODUCTION}

The Maritime Autonomous Surface Ship (MASS) is being developed under the active support of countries, especially in developed countries in the maritime technology fields such as the United States and the EU [1-5]. The UK submitted the information paper to the International Maritime Organization (IMO), requesting any necessity to establish regulatory framework for Marine Autonomous System (MAS) in response to the increasing use of the MAS [2]. Belgium, Germany, France, and European countries have established the Safety and Regulations for European Unmanned Maritime Systems (SARUMS) to provide a legal review of the operation, design, and regulation of the MASS operation [3]. The United States of America submitted a working paper that requests any membership states to contribute to definition of characteristics of the MASS, its services, and the Control and Non-Payload Communication (CNPC) for the purpose of developing communication system [4]. Norway, Japan, the United States and other countries summited to the IMO that the use of MASS creates the need

Revised Manuscript Received on July 22, 2019

Ho Namgung, Graduate School of Maritime Transportation System, Mokpo National Maritime University, Mokpo, Republic of Korea. Email: ngh2009@mmu.ac.kr

Kwang-Il Kim*, Division of Marine Industry and Maritime Police, Jeju National University, Jeju, Republic of Korea. Email: kki@jejunu.ac.kr

Keon Myung Lee, Faculty of Computer Science, Chungbuk National University, Cheongju, Republic of Korea. Email: kmlee@cbnu.ac.kr for a regulatory framework for such ships and their interaction and co-existence with manned ships [5]. Therefore, the process for the collision avoidance between the MASS and target ship has been proposed for ensuring safe navigation of the MASS [6-11]. The proposed process is able to divide into acquisition of information about the target ship and the situation analysis, inference of the collision avoidance through the calculated collision risk assessment, and taking an action after planning of the collision avoidance. However, ships navigating at sea are carrying out the action for the collision avoidance through collaboration by providing navigation intention messages to the target ship using telecommunication equipment such as Very High Frequency (VHF) radio telephone, Automatic Identification System (AIS) before taking an action for the collision avoidance. Therefore, if the MASS is only navigating the collision avoidance without taking an account of providing navigation intention messages with the target ship, it is able to maximize marine accidents because of being impossible to analyze intention of the MASS.

This research represents the efficient algorithm for transmitting navigation intention message in the encountering situation between the MASS and the target ship. The navigation system of the MASS decides the collision risk on the basis of the Fuzzy Inference System (FIS) on movements of target ship, and transmit navigation intention message. Section II presents the algorithm for navigation intention message transmission. Section III conducts simulation based on scenario, and section IV draws the conclusions.

\section{ALGORITHM DESIGN OF NAVIGATION INTENTION MESSAGE TRANSMISSION}

\section{A. Fuzzy Inference System}

The risk of collision means the degree of collision between the MASS and the target ship, and is a reference value of taking an action for the collision avoidance. In any encountering situation between the MASS and the target ship, taking an action for the collision avoidance is conducted on the basis of the risk of collision. In other words, the use of the risk assessment model for preventing collision occupies a large proportion [12,13].

The FIS, which can represent the collision risk by using these values as parameters, has been proposed since the ship can acquire information of DCPA (Distance to Close Points of Approach) and TCPA (Time to Close Points of 
Approach) in real time. Fuzzy logic is suitable for handling subjective concepts and language expressions [14,15]. However, the fuzzy membership function was constructed without taking into consideration the length and speed of both ship. In order to increase precise on the FIS, letting DCPA and TCPA to be dimensionless by using the length and speed of ship was conducted [16]. Figs. 1 and 2 show the fuzzy membership function of TCPA/(L/V) and DCPA/L, where $\mathrm{L}$ is the length of ship and $\mathrm{V}$ is the ship speed.

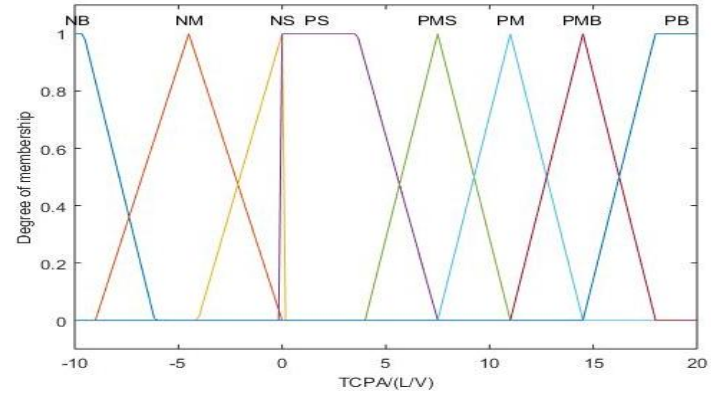

Fig. 1. Fuzzy membership function of TCPA/(L/V)

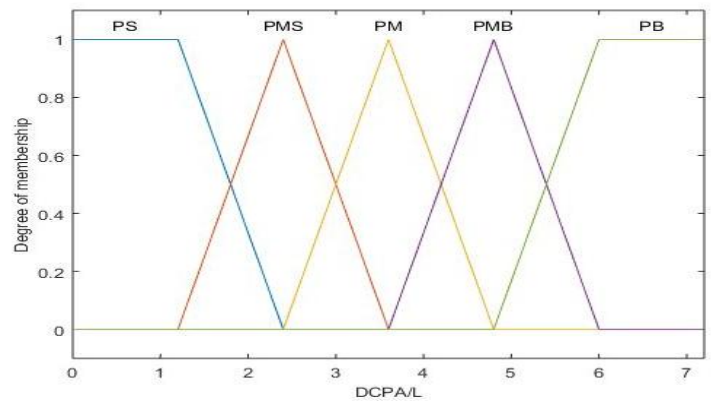

Fig. 2. Fuzzy membership function of DCPA/L

The reasoning rules of state variables used in the FIS are Small (S), Medium (M), B (Big), P (Positive), and N (Negative). Table- I shows the part where the risk assessment of collision is determined so that an input and an output can express the reasoning rule as a two-dimensional matrix. In other words, it is determined by the condition part of the i-th inference rule out of all the reasoning rules. Equation (1) shows the risk of collision at the conclusion as numerals in the fuzzy inference table.

$$
\text { Collision Risk(CR) }=\frac{\sum_{i=1}^{n} C R_{i} \cdot a_{i}}{\sum_{i=1}^{n} a_{i}}
$$

Where,

$n=$ number of reasoning rules,

$C R_{i}=$ singleton value of conclusion part of $i-$ th rule,

$a_{i}=$ contribution factor of conditional part of $i-$ th rule.

Table- I: Fuzzy inference table

\begin{tabular}{|c|c|c|c|c|c|c|c|c|c|}
\hline \multicolumn{2}{|c|}{ Division } & \multicolumn{7}{|c|}{ TCPA/L/V) } \\
\cline { 3 - 10 } & PS & -0.2 & -0.6 & -1.0 & 1.0 & 0.8 & 0.6 & 0.4 & 0.2 \\
\hline \multirow{4}{*}{ DCPA/L } & PMS & -0.2 & -0.2 & -0.6 & 0.8 & 0.6 & 0.4 & 0.2 & 0.2 \\
\cline { 2 - 10 } & PM & -0.2 & -0.2 & -0.2 & 0.6 & 0.4 & 0.2 & 0.2 & 0.2 \\
\cline { 2 - 10 } & PMB & -0.2 & -0.2 & -0.2 & 0.4 & 0.2 & 0.2 & 0.2 & 0.2 \\
\cline { 2 - 10 } & PB & -0.2 & -0.2 & -0.2 & 0.2 & 0.2 & 0.2 & 0.2 & 0.2 \\
\hline
\end{tabular}

\section{B. Methods of Collision Avoidance}

The FIS is only used to determine the role risk of collision. The matter of how to avoid collision between ships based on the reasoning of the risk of collision is an important part. Collision refers to a phenomenon where temporal and spatial positions coincide. In general, the collision avoidance is able to be divided into two methods. First it is used with spatial factor by adjusting own-ship course. Second it is used with time factor by adjusting own-ship speed. In the International Regulations for Preventing Collisions at Sea (COLREG)[17], it is recommended that both of them be coordinated.

In the COLREG, there are 13 to 17 rules for collision avoidance measures in case of encounters between ships [17]. Rule for the collision avoidance is shown as Fig. 3 and TableII. In case of the head-on situation which both ships encounter as facing status, both ships are obliged to avoid collision. In case of the crossing situation where one ship is crossing in front of another ship, ship having an extra area to turn to starboard side is obliged to avoid collision as a give-way ship. In case of the overtaking situation, a ship, which is overtaking from other ship's stern to other ship's ahead, becomes a give-way ship.

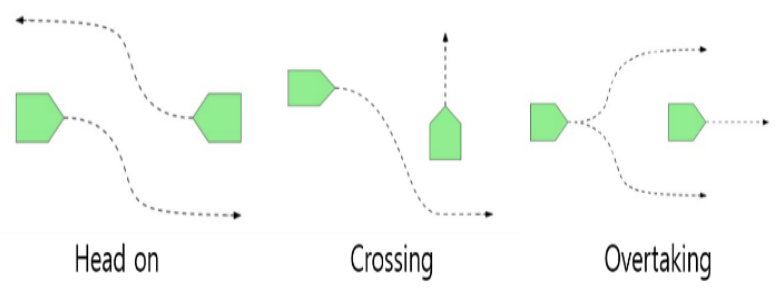

Fig. 3. Rules for ship collision avoidance

Table- II: Encounter situation

\begin{tabular}{|c|c|}
\hline Category & Relative bearing \\
\hline Head-on & Each $<5$ on the bow \\
Fine Crossing & Each $<15$, One $>5$ \\
Crossing & Each $<30$, One $>30$ \\
Bread Crossing & Each $<60$, One $>30$ \\
Converging Crossing & Each $<112.5$, One $>60$ \\
Converging Overtaking & Each $<150$, One $>112.5$ \\
Parallel Overtaking & One $>150$ \\
\hline
\end{tabular}

\section{Algorithm of Navigation Intention Message Transmission}

Based on the collision avoidance decision procedure of the MASS $[10,11]$, the following three stages can be divided.

In the first stage, the MASS continuously observes the movement of the target ships approaching the MASS during navigation, and judges whether the target ship is navigating within the range of the response of the collision avoidance based on the MASS. In order to determine the appropriate response distance, a study on the first-aid measures of the navigator [18] is used. Table- III shows the response distance for the collision avoidance based on the navigation relation proposed by the COLREG. In this study, we assume that the response distance is 6 nautical miles $(\mathrm{nm})$ in all navigation relation so that the MASS is able to prepare for making a decision appropriately. 
Table- III: Response distance for the collision avoidance

\begin{tabular}{|c|c|c|c|c|}
\hline \multirow{2}{*}{ Head-on } & \multicolumn{3}{|c|}{ Crossing } & \multirow{2}{*}{ Overtaking } \\
\cline { 2 - 4 } & Fine & Broad & Converging & \\
\hline $6 \mathrm{~nm}$ & $3 \mathrm{~nm}$ & $3 \mathrm{~nm}$ & $3 \mathrm{~nm}$ & $3 \mathrm{~nm}$ \\
\hline
\end{tabular}

Second step is to collect various information such as the target ship location information, speed information, course information, bearing information, distance information, and navigation information through Automatic Identification System (AIS), and calculates to the DCPA and TCPA. In case the output, which can be shown as the risk of collision, exceeds the threshold value by using the calculated DCPA and TCPA as input variables, the MASS should be judged by continuously observing a relative bearing between the MASS and the target ship, and decides whether the MASS is a give-way ship or not. At this time, we use the results of Cockcorft [19] and the first-aid measure of the navigator to specify the threshold [18]. The suggested safe distance is 1 nautical mile and the time to spare for altering course is about 10 minutes. Therefore, by calculating DCPA and TCPA for the proposed value, the value of the risk of collision was obtained to be 0.61 . In this study, we set the threshold for transmitting navigation intention message more than 0.6.

Third step integrates all kinds of information such as COLREG, DCPA, TCPA, the risk of collision, etc. for collision avoidance. And the MASS generates and transmits navigation intention messages for the collision avoidance in accordance with the COLREG. Fig. 4 shows the Algorithm of navigation intention message transmission.

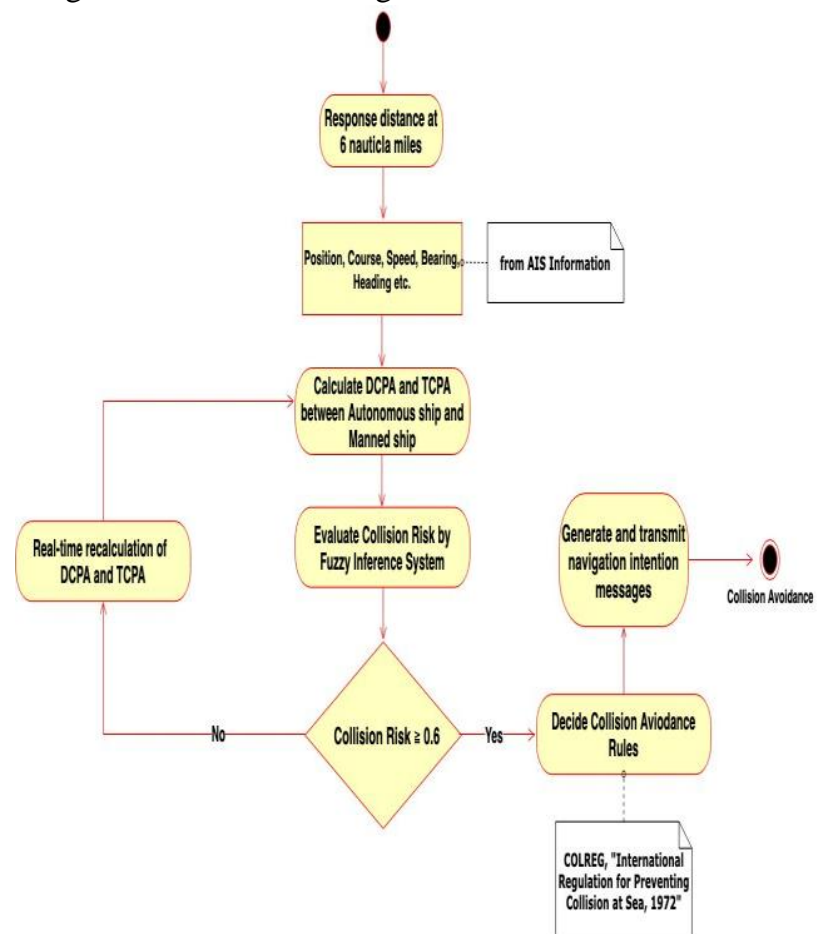

Fig. 4. Algorithm of navigation intention message transmission

\section{SIMULATION}

The following procedure was carried out to verify the proposed Algorithm. First, AIS data of Mokpo sea area were collected, and analyzed to obtain various information according to encounter situations between ships. One of which is designated as the MASS and the other as the target ship. Second, based on the extracted information, Matrix Laboratory (MATLAB) was used for purpose of calculating DCPA, TCPA, distance and bearing, assessment the risk of collision and making a decision for the collision avoidance. Fig. 5 shows the ship trajectory through the extraction of ship AIS data at Mokpo sea area.

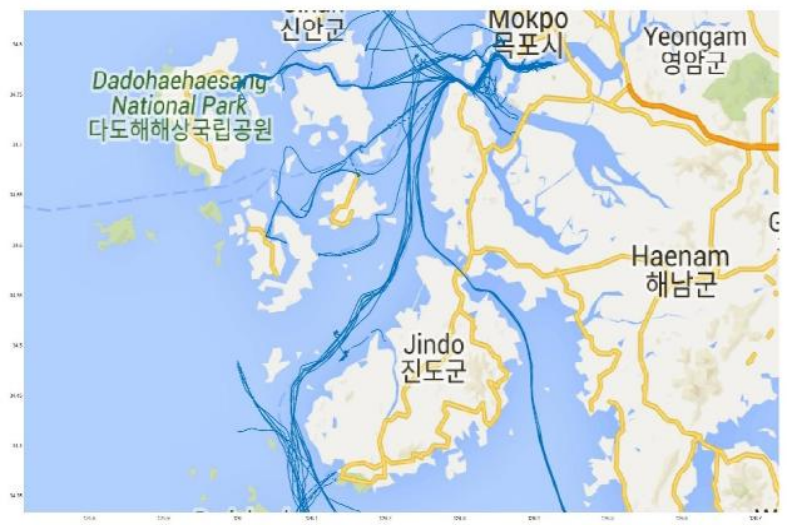

Fig. 5. Ship trajectory at Mokpo sea area

\section{A. Simulation Scenario}

The scenario was composed that the MASS detects position and related navigation information of the target ship and generates and transmits navigation intention message through AIS, which can transmit message with text, based on the proposed algorithm. Fig. 6 shows the scenario of encountering situation between the MASS and the target ship. The blue pentagram represents the MASS, and the red pentagram represents the target ship. Each number represents the ship trajectory in order. The MASS generates and transmits navigation intention messages for collision avoidance in the range of red square box, which is a collision hazard situation. Table IV shows the ship course and speed of the MASS and the target ship according to the each ship's trajectory.

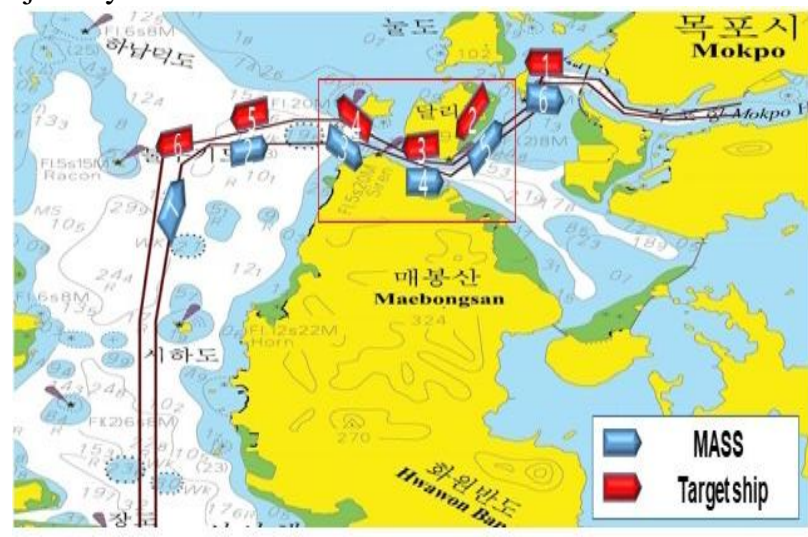

Fig. 6. Scenario of encountering situation between MASS and target ship 
Algorithm Design of Navigation Intention Message Transmission for Collision Avoidance of Maritime Autonomous Surface Vehicle

Table- IV: Ship course and speed according to trajectory

\begin{tabular}{|c|c|c|c|c|}
\hline \multirow{2}{*}{ Division } & \multicolumn{2}{|c|}{ MASS } & \multicolumn{2}{c|}{ Target ship } \\
\cline { 2 - 5 } & Course & Speed & Course & Speed \\
\hline No.1 & $042.2^{\circ}$ & $7.0 \mathrm{kts}$ & $296.7^{\circ}$ & $6.7 \mathrm{kts}$ \\
\hline No.2 & $071.3^{\circ}$ & $6.4 \mathrm{kts}$ & $271.5^{\circ}$ & $6.2 \mathrm{kts}$ \\
\hline No.3 & $103.1^{\circ}$ & $6.4 \mathrm{kts}$ & $248.3^{\circ}$ & $5.9 \mathrm{kts}$ \\
\hline No.4 & $092.1^{\circ}$ & $6.4 \mathrm{kts}$ & $267.3^{\circ}$ & $6.1 \mathrm{kts}$ \\
\hline No.5 & $064.8^{\circ}$ & $7.3 \mathrm{kts}$ & $334.5^{\circ}$ & $6.2 \mathrm{kts}$ \\
\hline No.6 & $136.7^{\circ}$ & $7.0 \mathrm{kts}$ & $250.1^{\circ}$ & $6.4 \mathrm{kts}$ \\
\hline
\end{tabular}

\section{B. Simulation Scenario}

Figs. 7 and 8 show the simulation results according to the scenarios. The black circle is the MASS, and the red circle is the target ship. Fig. 7 shows that the target ship is navigating within 6 nautical miles of the MASS, and Table- V shows the range, DCPA, TCPA, and the risk of collision. The value of the risk of collision was gradually increased according to the range change. Also, if the threshold for the risk assessment exceeded more than 0.6 , navigation intention messages for the collision avoidance was generated and transmitted to the target ship by determining whether the navigation relation according to the COLREG. Table- VI shows navigation relation and transmitted message. Each time of the collected information was calculated every 1 minute 30 seconds. Fig. 8 shows the situation in which collision avoidance was conducted as port to port according to the COLREG.

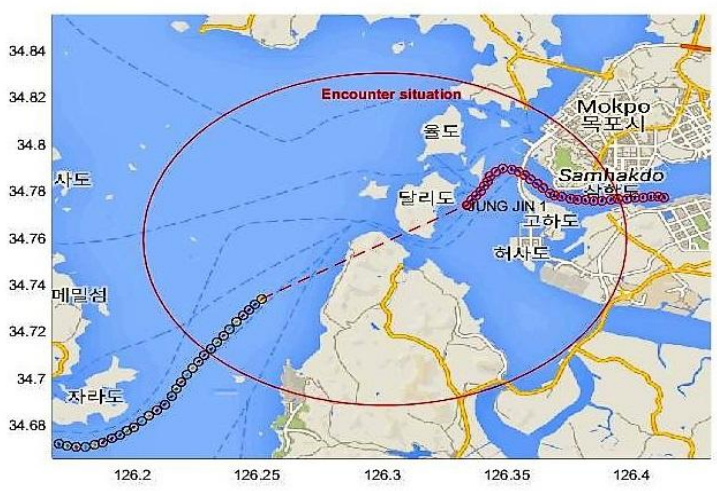

Fig. 7. Encountering situation at 6 nautical miles

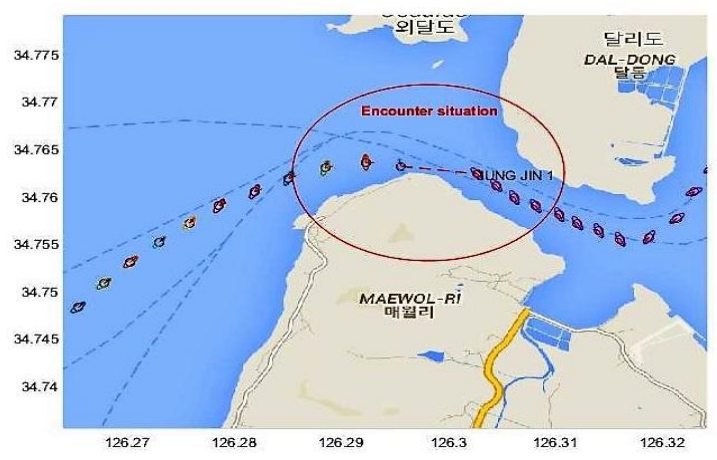

Fig. 8. Encountering situation at 1 nautical mile

Table- V: Encountering data in real time

\begin{tabular}{|c|c|c|c|c|}
\hline Time & Range(nm) & DCPA/L & TCPA/(L/V) & CR \\
\hline 00:46:01 & 5.68 & 0.14 & 10.7 & 0.61 \\
\hline $00: 47: 40$ & 5.37 & 0.12 & 10.4 & 0.62 \\
\hline 00:49:20 & 5.05 & 0.11 & 9.85 & 0.66 \\
\hline 00:51:01 & 4.72 & 0.11 & 9.07 & 0.71 \\
\hline
\end{tabular}

\begin{tabular}{|c|c|c|c|c|}
\hline $00: 52: 41$ & 4.41 & 0.11 & 8.27 & 0.76 \\
\hline $00: 54: 21$ & 4.09 & 0.11 & 7.24 & 0.80 \\
\hline $00: 56: 01$ & 3.79 & 0.09 & 6.62 & 0.81 \\
\hline $00: 57: 40$ & 3.21 & 0.09 & 6.12 & 0.82 \\
\hline $00: 59: 21$ & 2.93 & 0.08 & 5.42 & 0.85 \\
\hline $01: 01: 00$ & 2.67 & 0.08 & 4.38 & 0.91 \\
\hline
\end{tabular}

Table- VI: Sending message according to encountering situation

\begin{tabular}{|c|c|c|c|}
\hline Time & \multicolumn{2}{|c|}{ Encountering situation } & Message \\
\hline 00:46:01 & Broad crossing & Give-way & \multirow{10}{*}{$\begin{array}{c}\text { Navigate with } \\
\text { caution. I am } \\
\text { altering my } \\
\text { course to } \\
\text { starboard. }\end{array}$} \\
\hline $00: 47: 40$ & Broad crossing & Give-way & \\
\hline $00: 49: 20$ & Broad crossing & Give-way & \\
\hline $00: 51: 01$ & Broad crossing & Give-way & \\
\hline $00: 52: 41$ & Broad crossing & Give-way & \\
\hline $00: 54: 21$ & Broad crossing & Give-way & \\
\hline 00:56:01 & Broad crossing & Give-way & \\
\hline $00: 57: 40$ & Broad crossing & Give-way & \\
\hline 00:59:21 & Broad crossing & Give-way & \\
\hline 01:01:00 & Broad crossing & Give-way & \\
\hline
\end{tabular}

\section{CONCLUSION}

In this paper, we proposed an algorithm that was able to generate and transmit navigation intention messages by the MASS according to the encountering situation. The fuzzy inference system was utilized for reasoning of the risk of collision by using calculated DCPA and TCPA. In case the value of the reasoning of the risk of collision exceeded the designated threshold values (0.6), the MASS generated and transmitted navigation intention message to the target ship for collision avoidance. At the encountering situation, it was possible for the target ship to analyze the MASS navigation intention in advance. In the future research, it is necessary to implement the simulation taking into consideration encountering situation by multiple target ships. At this time, it should be also considered to detect the target ship with the highest risk of collision and to make a decision for the collision avoidance.

\section{ACKNOWLEDGMENT}

This work was supported by the research grant of Jeju National University in 2019.

\section{REFERENCES}

1. Ørnulf Jan Rødseth, Åsmund Tjora, and Pål Baltzersen, MUNIN Deliverable D4.5: Architecture specification, available at http://www.unmanned-ship.org, MRTK, MUNIN-FP7 GA-No.314286, Aug. 2013.

2. Smith, IMO MSC, "The IMO regulatory framework and its application to Marine Autonomous Systems," MSC 95/INF.20, Apr. 2015.

3. European Defence Agency Research and Technology, Best Practice Guide for Unmanned Maritime Systems Handling, Operations, Design and Regulations, SARUMS 2015, July 2015.

4. ITU-R, "Working document toward a preliminary draft new report ITU-R M.[MAR-UMS]," WP5B13-53-R1, Sept. 2015.

5. IMO MSC, "Maritime Autonomous Surface Ships Proposal for a regulatory scoping exercise," MSC 98/20/2, Feb. 2017. 
6. Jacoby Larson, Michael Bruch, and John Ebken. Autonomous navigation and obstacle avoidance for unmanned surface vehicles. Technical report, SPACE AND NAVALWARFARE SYSTEMS CENTER SAN DIEGO CA, 2006.

7. Giuseppe Casalino, Alessio Turetta, and Enrico Simetti. A three-layered architecture for real time path planning and obstacle avoidance for surveillance usvs operating in harbour fields. In Oceans 2009-Europe, pages 1-8. IEEE, 2009.

8. Sable Campbell, Wasif Naeem, and George W Irwin. A review on improving the autonomy of unmanned surface vehicles through intelligent collision avoidance manoeuvres. Annual Reviews in Control, 36(2):267-283, 2012.

9. Jongho Shin, Dong Jun Kwak, and Young-il Lee. Adaptive path following control for an unmanned surface vessel using an identified dynamic model. IEEE/ASME Transactions on Mechatronics, 2017.

10. Zbigniew, P. "Decision making in autonomous shipping - challenges," Autonomous Ship technology Symposium, June, 2018

11. NK Class, Guidelines for Concept Design of Automated Operation/Autonomous Operation of ships (Provisional Version), May, 2018.

12. Kim, K.I.; Lee, K.M. Ship Encounter Risk Evaluation for Coastal Areas with Holistic Maritime Traffic Data Analysis, Adv. Sci. Lett. 2017, 23, 9565-9569.

13. Kim, K. I.; Jeong, J. S.; Lee, B. G. Study on the analysis of near-miss ship collisions using logistic regression. Journal of advanced computational intelligence and intelligent informatics 2017, 21 (3), 467-473.

14. Hasegawa, K. et al.(1989), "Ship Auto-navigation Fuzzy Expert System (SAFES)," Journal of the Society of Naval Architecture of Japan, Vol.166.

15. Hasegawa K. "Automatic Collision Avoidance System for Ships using Fuzzy Control", In: Proceedings of the 8th Ship Control System Symposium. 1987

16. Lee HJ, Rhee KP. "Development of collision avoidance system by using expert system and search algorithm," International Shipbuilding Progress 2001;48(3):197-212.

17. IMO. Convention on the international regulations for preventing collisions at sea, 1972.

18. Y.S, Lee, J.M. Park, and Y.J. Lee, "A Study on the Initial Action of Navigators to Avoid Risk of Collision at Sea," Journal of Korean Navigation and Port Research, Vol.38, No.4, 2014. Available from: http://www.glonav.org/journal/article.php?code $=13061$

19. Cockcroft, A. N. and Lameijer, J. N. F., A Guide to the Collision Avoidance Rules, 6th edition, Elsevier, 2001.

\section{AUTHORS PROFILE}

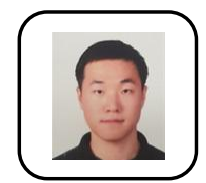

Ho Namgung is a Ph.D. candidate in Graduate school of Maritime Transportation at Mokpo National Maritime University in Korea. He received his B.S. degree in Nautical Science from Mokpo National Maritime University in Korea in 2009 and his M.S. degree in International Maritime Transportation Sciences from Mokpo National Maritime University in Korea in 2016

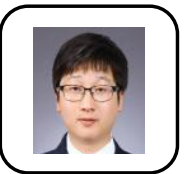

Kwang-Il Kim is a professor in the College of Ocean Science, Jeju National University, Korea. He received his B.S., M.S., and Ph.D. in Maritime Information System Engineering from Mokpo National Maritime University, Mokpo Korea, in 2005, 2010, and 2012, respectively. He was a research professor at Chungbuk National University.

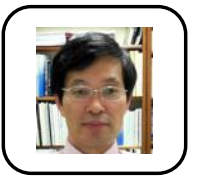

Keon Myung Lee is a professor in the Department of Computer Science, Chungbuk National University, Korea. He received his B.S., M.S., and Ph.D. degrees in computer science from KAIST, Korea and was a postdoctorate fellow at INSA de Lyon, France. He was a visiting professor at the University of Colorado at Denver and a visiting scholar at Indiana University, USA. His principal research interests are data mining, machine learning, soft computing, big data processing, and intelligent service systems. 